\title{
A call to safeguard sexual and reproductive health information and services during Ebola outbreaks
}

\author{
Nguyen Toan Tran ${ }^{1,2^{*}} \mathbb{D}$, Désirée Lichtenstein ${ }^{3}$, Benjamin Black ${ }^{4}$, Alice Rosmini ${ }^{5}$ and Catrin Schulte-Hillen ${ }^{3}$
}

\begin{abstract}
The recent Ebola virus disease (EVD) outbreaks in 2021 exemplify how sexual and reproductive health services are too often considered unessential during health emergencies. Bleeding for reasons other than EVD, such as pregnancy complications or rape, can be construed as EVD symptoms, reinforcing fear and stigmatisation, and delaying timely access to adequate care. In this commentary, we urgently call on all humanitarian actors to integrate the Minimum Initial Services Package for Sexual and Reproductive Health in Crisis Situations into current and future EVD preparedness and response efforts.
\end{abstract}

\section{Background}

Sexual and reproductive health (SRH) conditions are among the leading causes of mortality in women of reproductive age, with countries beset by fragility and lowresilience health systems accounting for two-thirds of maternal deaths worldwide [1]. Ebola virus disease (EVD) is a severe zoonotic illness with an average case fatality rate of $50 \%$. It spreads among humans through bodily fluids. Past EVD outbreaks suggest that halting health-care services judged to be unrelated to the epidemic response caused more deaths than did the epidemic itself [2].

At the intersection of EVD and SRH, poor health outcomes arise from the disruption of life-saving services, including maternal and neonatal care and care for individuals experiencing abortion complications, sexual violence, and other forms of gender-based violence [3]. Women and girls are at risk of gender-based violence due to increased exposure to perpetrators during curfews, school closure, and economic hardship, among

\footnotetext{
* Correspondence: nguyentoan.tran@uts.edu.au

${ }^{1}$ Australian Centre for Public and Population Health Research, Faculty of

Health, University of Technology Sydney, Sydney, NSW, Australia

${ }^{2}$ Faculty of Medicine, University of Geneva, Geneva, Switzerland

Full list of author information is available at the end of the article
}

others [4]. The mortality among EVD-positive pregnant women is not higher than that of non-pregnant individuals with EVD [5]. However, almost all EVD-affected pregnancies end in miscarriage, stillbirths, or neonatal deaths [6]. EVD-positive pregnant women can show signs and symptoms not meeting EVD case definitions [7]. Conversely, bleeding for reasons other than EVD, such as pregnancy, rape, and menses, can be misinterpreted as EVD symptoms, reinforcing fear and stigmatisation by the community and health-care providers, delaying timely access to adequate care [8].

The 2021 EVD outbreaks in Guinea and the Democratic Republic of Congo exemplify how regional and national humanitarian actors must actively safeguard SRH interventions in contingency plans, resource mobilisation, and responses. Consequently, the Inter-Agency Working Group for Reproductive Health in Crises issued field guidance on SRH and EVD [9]. The guidance builds on the prerequisite that health ministries and humanitarian stakeholders, including SRH leaders, should coordinate and plan to ensure that EVD preparedness and response integrate SRH services, supplies, and referral mechanisms. To enable the systematic prioritisation of SRH in current and future EVD responses-and 
minimise SRH-related deaths-the following recommendations should also be considered.

First, all essential services and supplies defined by the Minimum Initial Services Package (MISP) for $\mathrm{SRH}$ in Crisis Situation, a standard in humanitarian response, should be prioritised during the whole EVD response [10]. It includes intrapartum care, emergency obstetric and neonatal care, post-abortion care, safe abortion care to the full extent of the law, contraception, care for rape survivors, and prevention and treatment of HIV and other sexually-transmitted infections. Women and adolescent girls with suspected EVD should be offered pregnancy testing at EVD triage posts-backed by standard operating procedures that guarantee safe and dignified isolation until EVD ascertainment and effective referrals of confirmed cases to EVD treatment centres [11]. These centres should have adequate SRH supplies, personnel, and protocols, including for emergency obstetric and neonatal care, and offer counselling on potential outcomes and options to individuals testing positive for EVD and pregnancy. Equally important is safer sex and contraceptive counselling for all individuals of reproductive age, regardless of EVD and pregnancy status.

Second, engaging health-care workers, EVD survivors, and representatives of the community and targeted audiences is crucial for crafting clear and relevant public health information. This information should reiterate the importance of seeking care for childbirth and other SRH needs and medical emergencies. Risk communication and community engagement strategies should cover SRH and EVD, the risk of poor health outcomes for women and girls, help individuals differentiate "inexplicable bleeding" (EVD) from "explicable bleeding" (e.g., menses) - and address related stigma. No less critical is information about contraception, safer sex, breastfeeding, avoiding unsafe home births, and where to access care, including for Ebola virus vaccine.

Third, infection prevention and control measures, including personal protective equipment, should be part of managing labour and deliveries, abortion-related care, and any procedures with bodily fluid contact, such as rape survivor care, regardless of EVD status. Reliable supplies to enforce such precautions in both EVD treatment centres and SRH facilities should be thoroughly planned during coordination meetings. These facilities should also optimise waste management practices of used menstrual hygiene products and pregnancy-related fluids and tissues, including safe placenta disposal. Not least, SRH providers, including community midwives and other frontline health-care workers, must be prioritized in national Ebola vaccination programmes.

\section{Conclusion}

Our guidance on SRH and EVD was issued to galvanise country and regional stakeholders to safeguard essential health-care services, including SRH, during EVD preparedness and response efforts. We call upon them to treat life-saving SRH services as core constituents of the overall EVD intervention package, one that does not enfeeble but bolsters health-care systems while meeting the health needs of women, girls, and the whole community.

\section{Abbreviations}

EBD: Ebola virus disease; SRH: Sexual and reproductive health

\section{Acknowledgments}

We wish to thank the members of the Inter-Agency Working Group for Reproductive Health in Crises, the World Health Organization, United Nations Population Fund, and Médecins sans Frontières who offered their support, insights, and contributions.

\section{Authors' contributions}

NTT, CSH, and DL conceptualized the paper. NTT wrote the first draft with inputs from BB, AR, CSH, and DL. All authors contributed to the subsequent drafts and agreed on the final version.

Funding

Not applicable.

Availability of data and materials Not applicable.

\section{Declarations}

Ethics approval and consent to participate

Not applicable.

Consent for publication

Not applicable.

Competing interests

The authors have no competing interests to declare.

\section{Author details}

${ }^{1}$ Australian Centre for Public and Population Health Research, Faculty of Health, University of Technology Sydney, Sydney, NSW, Australia. ${ }^{2}$ Faculty of Medicine, University of Geneva, Geneva, Switzerland. ${ }^{3}$ United Nations Population Fund, Humanitarian Office, Geneva, Switzerland. ${ }^{4}$ Médecins Sans Frontières, Doctors Without Borders (MSF), London, UK. ${ }^{5}$ United Nations Population Fund, West and Central Africa Regional Office, Dakar, Senegal.

Received: 21 June 2021 Accepted: 28 June 2021

Published online: 10 July 2021

\section{References}

1. World Health Organization. Maternal mortality: levels and trends 2000-2017; Estimates from WHO, UNICEF, UNFPA, World Bank Group and the United Nations population division. Geneva: World Health Organization; 2017.

2. McQuilkin PA, Udhayashankar K, Niescierenko M, Maranda L. Health-care access during the Ebola virus epidemic in Liberia. Am J Trop Med Hygiene. 2017;97(3):931-6.

3. Sochas L, Channon AA, Nam S. Counting indirect crisis-related deaths in the context of a low-resilience health system: the case of maternal and neonatal health during the Ebola epidemic in Sierra Leone. Health Policy Plan. 2017;32(suppl_3):iii32-9.

4. Onyango MA, Resnick K, Davis A, Shah RR. Gender-based violence among adolescent girls and young women: a neglected consequence of the West African Ebola outbreak. In: Pregnant in the Time of Ebola: Springer; 2019. p. $121-32$. 
5. Foeller ME, do Valle CCR, Foeller TM, Oladapo OT, Roos E, Thorson AE. Pregnancy and breastfeeding in the context of Ebola: A systematic review. Lancet Infect Dis. 2020;20:e149.

6. Bebell LM, Oduyebo T, Riley LE. Ebola virus disease and pregnancy: a review of the current knowledge of Ebola virus pathogenesis, maternal, and neonatal outcomes. Birth Defects Res. 2017;109(5):353-62.

7. Pavlin BI, Hall A, Hajek J, Raja MA, Sharma V, Ramadan OP, et al. Atypical clinical presentation of Ebola virus disease in pregnancy: implications for clinical and public health management. Int J Infect Dis. 2020;97:167-73.

8. McKay G, Black B, Mbambu Kahamba S, Wheeler E, Mearns S, Janvrin A. Not all that bleeds is Ebola: how has the DRC Ebola outbreak impacted sexual and reproductive health in north-Kivu. New York: The International Rescue Committee; 2019.

9. Inter-Agency Working Group on Reproductive Health in Crises (IAWG). Ebola Virus Disease (EVD) \& Sexual and Reproductive Health (SRH): Operational Guidance. New York: IAWG; 2021. Available: https://iawg.net/resources/ ebola-virus-disease-evd-sexual-and-reproductive-health-srh-operationalguidance. Accessed 15 May 2021

10. Inter-Agency Working Group on Reproductive Health in Crises (IAWG). Minimum Initial Service Package (MISP). New York: IAWG; 2018. https://ia wgfieldmanual.com/manual/misp. Accessed 15 May 2020

11. World Health Organization. Interim infection prevention and control guidance for care of patients with suspected or confirmed filovirus haemorrhagic fever in health-care settings, with focus on Ebola. Geneva: World Health Organization; 2014

\section{Publisher's Note}

Springer Nature remains neutral with regard to jurisdictional claims in published maps and institutional affiliations.

Ready to submit your research? Choose BMC and benefit from:

- fast, convenient online submission

- thorough peer review by experienced researchers in your field

- rapid publication on acceptance

- support for research data, including large and complex data types

- gold Open Access which fosters wider collaboration and increased citations

- maximum visibility for your research: over $100 \mathrm{M}$ website views per year

At $\mathrm{BMC}$, research is always in progress.

Learn more biomedcentral.com/submissions 